\title{
MODELING AND PULPING VARIABLES OPTIMIZATION OF ETHANOL-ALKALI PULPING AND DELIGNIFICATION OF GREVILLEA ROBUSTA IN ETHIOPIA BY RESPONSE SURFACE METHODOLOGY
}

\author{
Temesgen ABETO AMIBO ${ }^{1, *}$ \\ ${ }^{1}$ School of Chemical Engineering, Jimma University, Institute of Technology Jimma, Ethiopia
}

\begin{abstract}
In this research, the raw material Grevillea robusta is used for the production of pulp and paper through ethanol-alkali pulping processes. Grevillea robusta is available in all parts of the southwestern, particularly Jimma, Bonga Ethiopia. The raw material of Grevillea robusta was characterized after pre-treatment. The central composite design, response surface methodology was used for the data analysis, and four independent variables such as temperature, ethanol concentration, active alkali and pulping time were considered for the optimization process. Independent variables were ranged from $120^{\circ} \mathrm{C}-200^{\circ} \mathrm{C}, 30 \mathrm{~min}-230 \mathrm{~min}, 5 \%-25 \%$, and $15 \%$ $75 \%$ for a factor such as a temperature, pulping time, active alkali, and ethanol concentration during the experiment. In this analysis, four responses (dependent variable) of pulp were also analyzed, such as pulp yield, brightness, whiteness, and kappa number. The pulp and paper produced have been characterized by standard methods. Besides, there were four dependent variables obtained within the range of $34.68 \%-58.31 \%, 45.56 \%-72.49 \%, 15.78 \%-37.18 \%$, and 11.2-18.9 for pulp yield, brightness, whiteness, and kappa. The dependent variable was significantly affected by all independent variables and its p-value was less than 0.05. The optimized process variable was $159.73^{\circ} \mathrm{C}, 41.17 \%, 16.79 \%$, and 132.26 minutes for temperature, ethanol concentration, active alkali, and pulping time. Optimized results for pulp yield, brightness, whiteness, and kappa number were $57.79 \%, 71.30 \%, 28.46 \%$, and 18.48 respectively. The desirability of the optimized outcomes was 0.8511 .
\end{abstract}

Keywords: Grevillea robusta; pulping process; optimization; characterization; response surface methodology.

\section{Introduction}

Paper is a sheet of material made up of cellulose material. Pulp and paper are produced from various plants by further processing of cellulose content obtained from grass, woods, or vegetable sources obtained from the water. The most abundant component of the native wood matrix is cellulose, a polysaccharide that is desired for pulp and paper production [1]. Paper production is the first time in East Asia, particularly in recent China around $105 \mathrm{BC}$. The paperlike item that was produced at that time is called the papyrus [2]. Paper, was originally manufactured in single sheets by hand, the paper is now produced by the use of complex and large machines, some making reels $10 \mathrm{~m}$ wider, running at $2000 \mathrm{~m}$ per minute and reaching about six thousand tons per year [3]. The first leading country in the pulp and paper industry is China and followed by United States [4]. The daily consumption of paper is increasing at an unparalleled rate. To answer to this demand, it is important to search for different plant species. When paper 
used for various documents, books, exercise books, and newspapers is produced in hard copies for different individuals around the world, the demand for paper increases [5].

Grevillea robusta is growing to the height of 5 to $40 \mathrm{~m}$ it is a fast-growing and evergreen tree that is found in most parts of Ethiopia. It is very tall and has dark grey barks also its leaves are fern-like structures and it's around $30 \mathrm{~cm}$ long [6]. It is a flowering plant, a taxonomy of species Grevillea robusta is under the domain of Eukaryota, and Genus of Grevillea [7]. The grevillea robusta tree can be used and produce fiber for pulp and paper industries under relatively short rotation; can grow adequately in a wide range of ecological conditions and sites among others [8]. Therefore, in our country, this Grevillea robusta is particularly available in the Oromo region, the Amara region, the South region, and the Tigre region. The other significance of this project is the development of pulp and paper from this plant in our country [9]. This helps to minimize the quantity of pulp imported from abroad. Besides, this will improve our country's economy as well as mitigate problems related to the production of pulp and paper [10]. High focus is put on afforestation in the sense of the new Millennium Development Goals in Ethiopia. In 2020, approximately 5 billion trees were planted in Ethiopia during the season. During the reforestation process, Grevillea robusta is a highly planted tree in Ethiopia. It accounts for approximately $50 \%$ of the total trees planted [11].

For this study, Design of expert (V.11) software that used for improvements of products and process helps to achieve the interaction effects of each of the variables, 2D graphics and 3D plots. The central composite design (CCD) of the surface methodology was used to evaluate the experimental results. The general objective of this study is to optimize the modeling and pulping variables (namely temperature, the concentration of ethanol, the concentration of alkali, and cooking time) to obtain the optimum pulp yield for paper production using the response surface methodology. Using five levels, four variables, and a total of thirty experiments was carried out. By using the combination of the above factors the four responses were obtained such as yield, kappa number, brightness, and whiteness of pulp and paper. The temperature was adjusted at $120^{\circ} \mathrm{C}, 140^{\circ} \mathrm{C}, 160^{\circ} \mathrm{C}, 180^{\circ} \mathrm{C}$, and $200^{\circ} \mathrm{C}$ for this study. These values were selected based on the literature review of previous documents. The ethanol concentration formulation was $15 \%, 30 \%$, $45 \%, 60 \%$, and $75 \%$. The concentrated sodium hydroxide( alkali concentration) was diluted to the concentration of $5 \%, 10 \%, 15 \%, 20 \%$, and $25 \%$. The pulping time means that the raw material or sample has been digested during a given period inside the autoclave digester. It's was adjusted at 30 minutes, 80 minutes, 130 minutes, 180 minutes, and 230 minutes. Finally, the results like yield, kappa number, brightness, whiteness, and other responses of pulp were analyzed by using response surface methodology.

\section{Materials and methods}

A hand saw was used to reduce the size of the stem on the basis of the length required. The axes used to minimize large-sized into small size. Crusher was used to turn the grossly sized sample into a fine-sized sample. The crucible, mortar, and pistil were the other components used during the experiment. The muffled furnace was used to determine the ash content of the sample. Digital weighing balance was used for one experiment to calculate the sample weight. In addition to assessing the moisture content, a digital oven or drier was used to drying purpose. The autoclave digester has been used to convert large materials, such as cellulose, into pulp components. The Erlenmeyer flask was used for holding sample. For filtration purposes, the filter paper was used. A water bath, beaker, heating mantle, measurement cylinder, and cellulose extraction thimble, Glove, sieve, blender unit, bucket, molding frame, pulp screen, and filter fabric were additional equipment needed during experiments.

The chemicals and reagents used in this analysis were: caustic soda $(\mathrm{NaOH})$, sodium sulfate $\left(\mathrm{NaSO}_{4}\right)$, hydrogen peroxide $\left(\mathrm{H}_{2} \mathrm{O}_{2}\right)$, distilled water, sulfuric acid $\left(\mathrm{H}_{2} \mathrm{SO}_{4}\right)$, sodium carbonate $\left(\mathrm{NaCO}_{3}\right)$, chlorine dioxide $\left(\mathrm{ClO}_{2}\right)$. 
The kraft pulping is a pulping process used to make wood pulp by using different chemical such as ethanol, sodium hydroxide, and other. Kraft pulping were conducted at Jimma University Institute of Technology, School of Chemical Engineering laboratory and the other part of Kraft pulping as well as characterization of parameters of pulp were done at chemistry department, JUCAV postharvest laboratory and school of mechanical engineering lab. In this study, different experiments was done. The first experiment was the production of basic pulping methods i.e. pulping relate to ethanolalkali pulping. In the second experiment were done thirty experiments based on ethanol alkali pulping. The third experiment was characterizing parameter by using the results of the first experiment done by the ethanol alkali pulping that is one type of kraft pulping process.

In this analysis, the raw material Grevillea robusta was transported to the School of Chemical Engineering laboratory in the sample preparation section from the area of its availability in the southwestern parts of Ethiopia around Jimma city. The first debark method was performed, which indicates that the bark of Grevillea robusta was removed for further processing by using an axe. With the use of a laboratory scale jaw crusher, the reduced samples were also changed to the finest powder. The crushed sample was screened using a mesh analysis. Again, the gross samples were recycled. The sample was prepared by proportion of the sample to the liquors or solvents. The fine powder of the prepared sample was placed in the Erlenmeyer flask of $500 \mathrm{ml}$. The solution of prepared sodium hydroxide and ethanol was stored in this Erlenmeyer flask according to the formulation prepared on the basis of the surface response mythology process. Based on its procedure, the autoclave digester of $15 \mathrm{~L}$ stainless steel was adjusted and the temperature was controlled by thermostats.

The pulp produced was characterized and distinguished by the use of different standard methods. The raw material was washed to remove adhering materials from the sample using hot water. Then, to reduce the moisture content of the sample, it was placed in the oven at $105^{\circ} \mathrm{C}$ for 32 hours. This sample was then ground to a suitable size by the jaw crusher and separated using 40 to 60 mesh sizes. This means that the sample went through the size of 60 mesh and was kept on a 40 mesh sieve. The raw material characterization was conducted by the American Society for Research and Materials (ASTM) and Technical Association of Pulp and Paper Industries (TAPPI) in Table 1 [14-18].

Table 1. ASTM and TAPPI methods used for Grevillea robusta characterization

\begin{tabular}{ll}
\hline Components to be characterized & Standards for each characterization \\
\hline Holocellulose in extractive powder & TAPPI standard T 9m-51 \\
$\alpha$-cellulose holocellulose & TAPPI T 203 \\
$\beta$-cellulose & TAPPI T 203 \\
Ash content & ASTM D 1102-84 \\
Lignin & ASTM D 1106-56 \\
Hot water solubility & TAPPI T 207 \\
Coldwater solubility & TAPPI T 207 \\
Alcohol-benzene solubility & ASTM D 1106-56 [14-20] \\
\hline
\end{tabular}

\section{Pulp and paper characterization}

The pulp produced was characterized by kappa number, brightness, whiteness, tensile strength, tear stress and viscosity. Various methods are used to characterize the pulp produced in this experiment, such as (TAPPI) and (ASTM). Using the yield formula of equation (1), the yield of the pulp produced was determined. Brightness is the diffusive reflectance of blue light from the pulp pad that should pass through a different band of lights at a wavelength of 457 nanometers it was determined by TAPPI T 452. Kappa number was characterized by using standard methods of TAPPI $236 \mathrm{~cm}-85$ [15]. The moisture content was measured and determined by TAPPI T 550. The viscosity of the pulp and paper was measured and standardized by using TAPPI T 402. 


$$
\text { Yield }(\%)=\frac{\text { mass of pulp Obtained }}{\text { Intial mass of sample }} \times 100 \%
$$

\section{Pulping process of grevillea robusta}

The Grevillea robusta pulping laboratory experiments were performed in a $15 \mathrm{~L}$-sized stainless steel autoclave digester with heater, temperature and pressure controller. The optimization process was carried out with temperature control thermostats in a $100 \mathrm{~mL}$ stainless steel oil bath. Sodium hydroxide, ethanol and distilled water were used for the preparation of solvents for pulping process. The solution of active alkali and ethanol is also measured in the proportion to the solid load of the sample. Thus, the solvents to solid ratio was $10: 1(10 \mathrm{ml}$ of solvent was needed for $1 \mathrm{~g}$ of the solid load). The proportion of ethanol to active alkali concentration was one to one. The sample of prepared ethanol, alkali, and a solid sample of grevillea robusta was placed in the Erlenmeyer flask and then put into the autoclave digester then the temperature was adjusted. Other variables, must be controlled during pulping process in the autoclave as shown in Table 2 and four factors were vary as shown in Table 3.

Table 2. Constant parameters the same throughout the experiments

\begin{tabular}{ll}
\hline Constant parameters & Its values for all experiments \\
\hline Pressure in bar & $8 \mathrm{bar}$ \\
The proportion of liquor and solid load & $10 \mathrm{ml}$ for each $1 \mathrm{~g}$ of solid load \\
\hline
\end{tabular}

Pressure for all experiments at 8 bar was controlled during the pulping process. Temperature is directly linked to the pressure from various literature reviews, which ensures that temperature increases and the pressure also rises proportionally. [12]. Thus, during the autoclave digestion process, the pressure was controlled.

Table 3. The experiments were carried out at different point of independent variable

\begin{tabular}{ll}
\hline \multicolumn{1}{c}{ Parameters } & \multicolumn{1}{c}{ Five levels of each factor } \\
\hline Temperature & $120^{\circ} \mathrm{C}, 140{ }^{\circ} \mathrm{C}, 160{ }^{\circ} \mathrm{C}, 180^{\circ} \mathrm{C}$, and $200{ }^{\circ} \mathrm{C}$. \\
Ethanol Concentration & $15 \%, 30 \%, 45 \%, 60 \%$, and $75 \%$. \\
Alkali Concentration & $5 \%, 10 \%, 15 \%, 20 \%$, and $25 \%$. \\
Cooking Time & 30 minutes, 80 minutes, 130 minutes, 180 minutes, and 230 minutes. \\
\hline
\end{tabular}

\section{Pulp and paper characterization}

ASTM and TAPPI techniques have been used to characterize the pulp and paper produced. . According to this study, the kappa number, brightness, whiteness, viscosity, tensile strength, and tear resistance of the pulp and paper characterized.

Table 4. Characterization of pulp and paper

\begin{tabular}{cc}
\hline Parameters used & Methods of characterization \\
\hline Tensile strength & TAPPI tests T-404 and T-494 \\
Tearing resistance & Edge-tearing strength (T-470) \\
Kappa number & TAPPI 236 cm-85 \\
Viscosity & TAPPI T230 om-94 \\
Brightness & TAPPI 525 om-92 \\
Whiteness & TAPPI 560 and T 562 [14-18] \\
\hline
\end{tabular}

\section{Experimental design}

To evaluate the experimental effects, design of expert (v.11) software was used to analyse response surface methodology. The response surface methodology is the best technique used to optimize the process variable. It was used to evaluate the factor that had a better effect on pulp yields. This helps to assess which factor was influence the yield significantly. To determine linear, 
interaction, and quadratic relationships between independent and dependent variables during pulp and paper optimization, to answer such questions the response surface methodology (CCD) was chosen. Based on equation (2), the CCD generates 30 data points, including 16-factor points, 8 -axial points, and 6-points as a center.

$$
N=2^{n}+2 n+n_{c}
$$

Where $\mathrm{N}$ is the number of experiments was carried out, $\mathrm{n}$ is the number of the independent variable, and $\mathrm{n}_{\mathrm{c}}$ is the number of replicates used to check the above-conducted experiment was either correct or not.

$$
Y=b_{o}+\sum_{i=1}^{n} b_{i} x_{i}+\sum_{i=1}^{n} b_{i i} x_{i}^{2}+\sum_{i=1}^{n-1} \sum_{j=i+1}^{n} b_{i j} x_{i j}
$$

Where $\mathrm{Y}$ is predicted responses for pulps yields, brightness, whiteness, and kappa numbers. The $\mathrm{n}$ implies that the number of independent variables used for pulp optimization. The coefficients like $b_{o}, b_{i}, b_{i i}, b_{i j}$ are constant coefficients, first-order (linear) coefficients, secondorder (quadratic) interaction coefficients, and second-order (quadratic) non-interaction coefficients.

\section{Bleaching, molding, and sheeting process of the pulp}

After the pulp was made, various bleaching techniques such as chlorine dioxide, extraction or washing, oxygen, hydrogen peroxide, ozone and chelate wash were used to bleach the pulp produced. The molding process was also carried out to provide the pulp with an appropriate thickness.

\section{Results and Discussion}

The raw material or chemical composition of Grevillea robusta has been characterized, the results obtained during laboratory tests have been presented, and the pulp produced has been characterized by various standard methods, such as the Technical Association of Pulp and Paper Industries (TAPPI) and the American Society for Testing and Materials (ASTM).

\section{Raw material characterization}

As shown below in Table 5, study of the chemical composition of Grevillea robusta. (ASTM D 1102-84) methods have been used to determine the quality of ash. Compared to other plant species such as Bambusa vulgaris bamboo, globulus, Yushania alpine, Eucalyptus globulus bark, Yushania alpine, and other species of plants, then Grevillea robusta has very low ash content. The ash content of the wood depends on a number of factors, such as the type of tree or shrub (i.e. bark or outer cover, wood or stem, leaves), the type of fuel used during characterization, the type of soil planted or the surrounding area [13]. For this study, the content of ash for Grevillea robusta was 0.79 , much lower than the ash content of Eucalyptus globulus wood and Eucalyptus globulus bark, Yushania alpine, Bambusa vulgaris, with values of 0.42 , $1.96,2.2$, and 2.3 reported by the results [14-16]. The lignin component for gravillia rubusta was measured using standard methods ASTM D 1106-56 and the lignin value obtained from the experiment was 22.35. Holocellulose is the key ingredient used for pulp processing and the TAPPI standard T 9m-51 was used to evaluate the paper and its value was 80.12 . This value means that there was a high amount of cellulose in gravillia rubusta. $\alpha$ and $\beta$-cellulose have been measured using standard TAPPI T 203. The findings were 46.38 and 19.12 respectively. Normal TAPPI methods were used to determine the solubility of hot water and the solubility of cold 
water . Its value was found to be 4.23 and 2.87 , respectively. The solubility wood sample was higher in hot water than in cold water. This was due to molecules are moving around faster in hot water than cold. The solubility of the solid sample was lower than that of the hotter [16]. The overall extractive value for this experiment was 3.38, which constitutes alcohol: benzene, alcohol, hot water; the values shown in Table 5 are 3.98, 0.56 and 0.84 , respectively.

\section{Factors affecting the yield and another parameter of the pulping process}

From the literature, the method of pulp and paper optimization is affected by multiple factors. Table 6 shows that the optimization pulping process is influenced by different factors, such as temperature, ethanol concentration, active alkaline loading, cooking time, types of plant specious used, and other factors affecting the optimization process. The research work published in 2014 on Eucalyptus globulus has three factors that affect the optimization process of pulp and paper products like temperature, cooking time, active alkali concentration, and the detailed information is shown in table 6. In 2018, another research on the optimization process for pulp and paper production from Ensete Ventricosum was affected by four different factors such as temperature, cooking time, active alkali concentration, and ethanol concentration. Besides this, in 2020 the research work on Yushania alpine (bamboo) the optimization of the pulping process was carried out its production process was affected by four different factors that are temperature, cooking time, active alkali concentration, and ethanol concentration.

Table 5. Chemical composition of Grevillea robusta characterizing in laboratory scale

\begin{tabular}{lcc}
\hline Components to be characterized & $\begin{array}{c}\text { Standards for each } \\
\text { characterization }\end{array}$ & Values Obtained \\
\hline Holocellulose in original wood & TAPPI standard T 9m-51 & 80.12 \\
$\alpha$ - holocellulose original wood & TAPPI T 203 & 46.38 \\
$\beta$-cellulose in original wood & TAPPI T 203 & 19.12 \\
Ash content & ASTM D 1102-84 & 0.79 \\
Lignin & ASTM D 1106-56 & 22.35 \\
Hot water solubility & TAPPI T 207 & 4.23 \\
Coldwater solubility & TAPPI T 207 & 2.87 \\
Total extractives & & 3.98 \\
Alcohol-benzene (1:2) proportion & ASTM D 1106-56 \\
Alcohol & ASTM D 1106-56 & 0.56 \\
Hot water & ASTM D 1106-56 & 0.84 \\
Total & & 3.38 \\
\hline
\end{tabular}

Table 6. The factors significantly affect the yield of pulp and paper

\begin{tabular}{ccccc}
\hline & \multicolumn{3}{c}{ Type of raw material used and the research conducted } \\
\cline { 2 - 5 } Factors & Eucalyptus globulus & $\begin{array}{c}\text { Ensete } \\
\text { Ventricosum }\end{array}$ & $\begin{array}{c}\text { Yushania } \\
\text { alpine }\end{array}$ & $\begin{array}{c}\text { Grevillea } \\
\text { robusta }\end{array}$ \\
\hline Temperature $\left({ }^{\circ} \mathrm{C}\right)$ & $143-177$ & $130-170$ & $140-220$ & $120-200$ \\
Cooking time $(\mathrm{min})$ & $40-140$ & $30-150$ & $120-200$ & $30-230$ \\
Alikali- concentration $(\%)$ & $12-28$ & $0-20$ & $10-30$ & $5-25$ \\
Ethanol concentration $(\%)$ & - & $20-60$ & $30-70$ & $15-75$ \\
& Neiva et al., [14] & Berhanu et & Aklilu, [15] & currentstudy \\
\hline
\end{tabular}

\section{Response surface methodology}

The response surface methodology for the central composite design matrix is shown in Table 7. From equation (2) the number of variables is four and the total number of experiments is 30. This total experiment is divided into three main parts: the factorial design, the axial run, and the central one. The factorial design consists of 16 experiments, the axial run consists of 8 experiments and is represented by its formula $2 \times 4$, and finally the center run has a 6 experiments. 


\section{Central composite design for pulp and paper optimization process}

The results obtained from the laboratory experiment were shown in Table 7. The results were obtained by using a combination of decoded variables. The coded variable is a variable that is assigned in a symbol and the decoded variable is a variable that has full names [19]. The four independent factors namely: temperature (Tem.), ethanol concentration (Eth.), alkali concentration (Alkali), cooking time (Time) used to determine the dependent variable like yield(Y), kappa number (KpN), brightness (Bright.) and whiteness (White.).

From Table 7 the dependent variable like yield(Y), kappa number $(\mathrm{KpN})$, brightness (Bright.), and whiteness (White.) is shown. These values obtained were analyzed by using analysis of variance (ANOVA). The experimental results were analyzed by using the level of significance ( $\alpha$ value) at 5\%. From Table 8 the F-value and p-value for models are listed. The pvalue helps to determine the significance and non-significance of all single factors as well as the interaction factors. The p-value obtained for pulp yield, brightness, kappa number, and whiteness for all models was much less than 0.0001. Besides this, the lack of a fit model for the yield of pulp, kappa numbers, brightness, and whiteness were 0.6880, 0.2396, 0.9810, and 0.4793 respectively. For all responses, the p-value were less than the level of significance ( $\alpha$ value) this indicate that the models are accepted [20]. But the lack of a fit model for all response was greater than the level of significance. Thus, it is not significant.

Table 7. The experimental results obtained for coded and decoded variables

\begin{tabular}{|c|c|c|c|c|c|c|c|c|c|c|c|c|}
\hline \multirow[t]{2}{*}{ Run } & \multicolumn{4}{|c|}{ Coded variable } & \multicolumn{4}{|c|}{ Decoded variable } & \multicolumn{4}{|c|}{ Dependent variable } \\
\hline & $\mathbf{A}$ & $\mathbf{B}$ & $\mathbf{C}$ & $\mathbf{D}$ & $\operatorname{Tem}\left({ }^{\circ} \mathrm{c}\right)$ & $\begin{array}{l}\text { Eth. } \\
(\%)\end{array}$ & $\begin{array}{l}\text { Alkali } \\
(\%)\end{array}$ & $\begin{array}{l}\text { Time } \\
(\mathrm{min})\end{array}$ & $\mathbf{Y}(\%)$ & $\mathrm{KpN}$ & $\begin{array}{l}\text { Bright. } \\
(\%)\end{array}$ & $\begin{array}{l}\text { White. } \\
(\%)\end{array}$ \\
\hline 1 & -1 & 1 & 1 & 1 & 140 & 60 & 20 & 180 & 42.46 & 20.93 & 57.12 & 26.61 \\
\hline 2 & 0 & 0 & 0 & 0 & 160 & 45 & 15 & 130 & 58.31 & 36.72 & 71.31 & 26.55 \\
\hline 3 & -1 & -1 & -1 & 1 & 140 & 30 & 10 & 180 & 45.45 & 24.35 & 68.34 & 19.12 \\
\hline 4 & 0 & 0 & 0 & 0 & 160 & 45 & 15 & 130 & 57.99 & 36.5 & 72.15 & 26.22 \\
\hline 5 & 0 & 0 & 0 & 0 & 160 & 45 & 15 & 130 & 58.3 & 37.05 & 71.86 & 26.82 \\
\hline 6 & 0 & $\begin{array}{l}- \\
\alpha\end{array}$ & 0 & 0 & 160 & 15 & 15 & 130 & 44.72 & 24.1 & 62.21 & 28.64 \\
\hline 7 & 0 & 0 & 0 & $\alpha$ & 160 & 45 & 15 & 230 & 34.89 & 17.99 & 60.01 & 27.31 \\
\hline 8 & 1 & 1 & 1 & 1 & 180 & 60 & 20 & 180 & 36.39 & 16.72 & 55.56 & 35.12 \\
\hline 9 & -1 & -1 & 1 & 1 & 140 & 30 & 20 & 180 & 45.53 & 22.32 & 62.82 & 28.08 \\
\hline 10 & 1 & -1 & 1 & -1 & 180 & 30 & 20 & 80 & 40.61 & 20.76 & 51.01 & 36.21 \\
\hline 11 & 0 & 0 & 0 & $-\alpha$ & 160 & 45 & 15 & 30 & 37.94 & 23.01 & 45.58 & 26.02 \\
\hline 12 & $-\alpha$ & 0 & 0 & 0 & 120 & 45 & 15 & 130 & 44.61 & 25.13 & 59.69 & 17.32 \\
\hline 13 & 1 & -1 & 1 & 1 & 180 & 30 & 20 & 180 & 39.08 & 18.73 & 58.01 & 37.18 \\
\hline 14 & -1 & -1 & 1 & -1 & 140 & 30 & 20 & 80 & 45.91 & 24.91 & 53.79 & 27.83 \\
\hline 15 & -1 & 1 & -1 & 1 & 140 & 60 & 10 & 180 & 41.81 & 24.72 & 61.54 & 16.67 \\
\hline 16 & 0 & $\alpha$ & 0 & 0 & 160 & 75 & 15 & 130 & 39.59 & 21.98 & 53.79 & 24.53 \\
\hline 17 & 1 & -1 & -1 & 1 & 180 & 30 & 10 & 180 & 40.59 & 19.91 & 60.74 & 27.81 \\
\hline 18 & 0 & 0 & 0 & 0 & 160 & 45 & 15 & 130 & 57.85 & 36.81 & 72.01 & 26.54 \\
\hline 19 & 0 & 0 & $\alpha$ & 0 & 160 & 45 & 25 & 130 & 48.59 & 23.14 & 55.49 & 35.89 \\
\hline 20 & 1 & 1 & 1 & -1 & 180 & 60 & 20 & 80 & 39.45 & 18.76 & 48.87 & 34.34 \\
\hline 21 & -1 & -1 & -1 & -1 & 140 & 30 & 10 & 80 & 45.73 & 27.12 & 60.29 & 17.78 \\
\hline 22 & 0 & 0 & - & 0 & 160 & 45 & 5 & 130 & 50.01 & 27.81 & 63.78 & 17.14 \\
\hline & & & $\alpha$ & & & & & & & & & \\
\hline 23 & 0 & 0 & 0 & 0 & 160 & 45 & 15 & 130 & 58.23 & 37.2 & 72.45 & 26.42 \\
\hline 24 & -1 & 1 & -1 & -1 & 140 & 60 & 10 & 80 & 43.32 & 26.97 & 54.99 & 15.78 \\
\hline 25 & -1 & 1 & 1 & -1 & 140 & 60 & 20 & 80 & 44.09 & 22.61 & 48.74 & 24.99 \\
\hline 26 & 1 & -1 & -1 & -1 & 180 & 30 & 10 & 80 & 41.98 & 21.95 & 54.81 & 26.98 \\
\hline 27 & 1 & 1 & -1 & -1 & 180 & 60 & 10 & 80 & 39.91 & 21.52 & 52.34 & 24.91 \\
\hline 28 & 1 & 1 & -1 & 1 & 180 & 60 & 10 & 180 & 37.21 & 19.43 & 57.78 & 25.81 \\
\hline 29 & 0 & 0 & 0 & 0 & 160 & 45 & 15 & 130 & 58.02 & 36.98 & 72.21 & 26.42 \\
\hline 30 & $\alpha$ & 0 & 0 & 0 & 200 & 45 & 15 & 130 & 34.68 & 15.73 & 52.61 & 35.58 \\
\hline
\end{tabular}

From Table 8 the model analyzed by using central composite design was highly significant this indicates that the regression of data fitting between experimental results and predicted values 
were in a good agreement. From Table 9 fit statistics data results of standard deviation, Mean, C.V (\%), $\mathrm{R}^{2}$, adjusted $\mathrm{R}^{2}$, predicted $\mathrm{R}^{2}$, and Adeq Precision were obtained. The results obtained for a standard deviation for pulp yield, kappa number, brightness, and whiteness were 0.1718 , $0.0924,0.2702$, and 0.2106 respectively. The coefficient of variation obtained for the responses was $0.3808,0.6067,0.4524$, and 0.7934 respectively. According to Owolabi et al.,[21]. the standard deviation and coefficients of variation were very low the data is accepted. For this study, the $\mathrm{CV}$ and standard deviation were low and acceptable with the good agreements. According to Owolabi et al., [21], the adjusted $\mathrm{R}^{2}$ and predicted $\mathrm{R}^{2}$ are in a good agreement below a $20 \%$ variance. The results of the modified $\mathrm{R}^{2}$ and the expected $\mathrm{R}^{2}$ were in the percentage of deviation given above.

Table 8. the F-value and p-value for models, factors, and response

\begin{tabular}{|c|c|c|c|c|c|c|c|c|}
\hline \multirow[t]{2}{*}{ Source } & \multicolumn{2}{|c|}{ Yield of pulp } & \multicolumn{2}{|c|}{ Kappa number } & \multicolumn{2}{|c|}{ Brightness } & \multicolumn{2}{|c|}{ Whiteness } \\
\hline & $\begin{array}{c}\text { F- } \\
\text { value }\end{array}$ & p-value & $\begin{array}{c}\text { F- } \\
\text { value }\end{array}$ & p-value & $\begin{array}{c}\text { F- } \\
\text { value }\end{array}$ & p-value & $\begin{array}{c}\text { F- } \\
\text { value }\end{array}$ & p-value \\
\hline Model & 4003.2 & $<0.0001$ & 1364.1 & $<0.0001$ & 1760.9 & $<0.0001$ & 5905.1 & $<0.0001$ \\
\hline A-Temp. & 4903.9 & $<0.0001$ & 5877 & $<0.0001$ & 1038.9 & $<0.0001$ & 1095.2 & $<0.0001$ \\
\hline B-Eth. & 1313.2 & $<0.0001$ & 13.93 & 0.0020 & 1410.0 & $<0.0001$ & 585.7 & $<0.0001$ \\
\hline C-Alkali. & 39.95 & $<0.0001$ & 218.32 & $<0.0001$ & 1512.8 & $<0.0001$ & 1198.5 & $<0.0001$ \\
\hline D-Time & 487.33 & $<0.0001$ & 1027.0 & $<0.0001$ & 4213.4 & $<0.0001$ & 96.89 & $<0.0001$ \\
\hline $\mathrm{AB}$ & 5.70 & 0.0306 & 89.12 & $<0.0001$ & 140.89 & $<0.0001$ & - & - \\
\hline $\mathrm{AC}$ & 72.22 & $<0.0001$ & 16.68 & 0.0010 & 93.83 & $<0.0001$ & - & - \\
\hline $\mathrm{AD}$ & 50.43 & $<0.0001$ & 110.7 & $<0.0001$ & 41.34 & $<0.0001$ & - & - \\
\hline $\mathrm{BC}$ & 16.13 & 0.0011 & 61.9 & $<0.0001$ & 4.11 & 0.0609 & - & - \\
\hline $\mathrm{BD}$ & 59.93 & $<0.0001$ & 122.4 & $<0.0001$ & 7.45 & 0.0155 & - & - \\
\hline $\mathrm{CD}$ & 1.10 & 0.3114 & 289.5 & $<0.0001$ & 22.53 & 0.0003 & - & - \\
\hline $\mathrm{A}^{2}$ & 19865. & $<0.0001$ & 3794.0 & $<0.0001$ & 5883.4 & $<0.0001$ & - & - \\
\hline $\mathrm{B}^{2}$ & 14839 & $<0.0001$ & 3881.8 & $<0.0001$ & 4588.6 & $<0.0001$ & - & - \\
\hline $\mathrm{C}^{2}$ & 4537.8 & $<0.0001$ & 2455.6 & $<0.0001$ & 3578.1 & $<0.0001$ & - & - \\
\hline $\mathrm{D}^{2}$ & 27410 & $<0.0001$ & 5739.9 & $<0.0001$ & 8641.4 & $<0.0001$ & - & - \\
\hline Lack of Fit & 0.7276 & 0.6880 & 0.0615 & 0.9998 & 0.2160 & 0.9810 & 1.15 & 0.4793 \\
\hline
\end{tabular}

Factors such as A, B, C, D, AB, AC, AD, BC, BD, CD, $\mathrm{A}^{2}, \mathrm{~B}^{2}, \mathrm{C}^{2}$, and $\mathrm{D}^{2}$ has been significant on the pulp yield, brightness, kappa number, and whiteness of the pulp. The suggested model was quadratic versus two-factor interaction for pulp yield, brightness, kappa number , and brightness, but the suggested model was linear for whiteness. Factors such as A, B, C, D, AB, $\mathrm{AC}, \mathrm{AD}, \mathrm{BC}, \mathrm{BD}, \mathrm{A}^{2}, \mathrm{~B}^{2}, \mathrm{C}^{2}$, and $\mathrm{D}^{2}$ have significant effects, and the $\mathrm{CD}$ factor has minor effects on pulp yield. In addition, the Kappa number was influenced by both the single factor and the interaction results. The brightness was influenced by both single factors and interaction effects, excluding BC interaction effects. Only the whiteness of the pulp was affected by single factors. Since the suggested model was liner, the interaction results had no or negligible effect on whiteness. From Table 9 the $\mathrm{R}^{2}$ values for pulp yield, kappa number, brightness, and whiteness were $0.997,0.998,0.993$, and 0.998 respectively. The $\mathrm{R}^{2}$ is approached to one, the experimental results and predicted values had a good fitting [35]. For this analysis, the findings were approached to 1 therefore the data had good fittings and were highly acceptable.

Table 9. Fit statistic analyzed yield of pulp, kappa number, brightness, whiteness

\begin{tabular}{lcccc}
\hline Fit statistic & Yield of pulp & Kappa number & Brightness & Whiteness \\
\hline Std. Dev. & 0.1718 & 0.0924 & 0.2702 & 0.2106 \\
Mean & 45.1083 & 15.23 & 59.73 & 26.5540 \\
C.V. $\%$ & 0.3808 & 0.6067 & 0.4524 & 0.7934 \\
R $^{2}$ & 0.9997 & 0.9987 & 0.9993 & 0.9989 \\
Adjusted R & 0.9994 & 0.9976 & 0.9988 & 0.9987 \\
Predicted R & 0.9989 & 0.9941 & 0.9983 & 0.9984 \\
Adeq Precision & 192.6679 & 114.91 & 137.8842 & 248.17 \\
\hline
\end{tabular}


By combining single variables, interaction effects, and individual interaction effects, the model equation represents pulp yield, kappa number, brightness, and whiteness. Model equation (4) was used to explain the pulp yield. The insignificant variables of the model equation have been removed. The constant number for the yield model equation was 58.12, which implies that the equation intercepts points. The plus sign indicates that the variables are directly related to the pulp yield, while the negative sign indicates that the optimization process was inversely related. All variables have coefficients; $\mathrm{A}, \mathrm{B}, \mathrm{C}, \mathrm{D}, \mathrm{AC}, \mathrm{AD}, \mathrm{BD}, \mathrm{C}^{2}, \mathrm{~A}^{2}, \mathrm{~B}^{2}$ and $\mathrm{D}^{2}$ had a negative relationship with the pulp yield. The yield of pulp had a positive relationship with the interaction effects of $\mathrm{AB}$ and BC. Similarly, the kappa number has an intercept of 36.88 from equation (5). Also, kappa number had a negative relationship with $\mathrm{A}, \mathrm{B}, \mathrm{C}, \mathrm{D}, \mathrm{BC}, \mathrm{A}^{2}, \mathrm{~B}^{2}, \mathrm{C}^{2}$, and $\mathrm{D}^{2}$. Kappa number had positive relationship with $\mathrm{AC}$ only. Factors such as $\mathrm{A}, \mathrm{B}, \mathrm{C}, \mathrm{AD}, \mathrm{BD}, \mathrm{CD}, \mathrm{C}^{2}, \mathrm{~A}^{2}$, $\mathrm{B}^{2}, \mathrm{D}^{2}$ had a negative relationship with the paper's brightness as shown from equation (6). The brightness has an intercept at a point was 72 . The other variables, such as $\mathrm{D}, \mathrm{AB}, \mathrm{AC}$, and $\mathrm{CD}$ have positively related to the paper's brightness. The whiteness of the paper had a posetive relationship with A, C, and D. whiteness had a negative relationship with B from equation (7).

$$
\begin{array}{rl}
Y(\%)=58.12- & 4.91 A-1.27 B-0.2217 C-0.7742 D+0.2050 A B \\
& -0.7300 A C-0.6100 A D+0.1725 B C-0.3325 B D-18.49 A^{2} \\
& -4.00 B^{2}-2.21 C^{2}-5.43 D^{2} \\
& \\
K=18.75-2.89 A-0.0704 B-0.2788 C-0.6046 D-0.4362 A B+0.1888 A C \\
+ & 0.4863 A D-0.1819 B C-0.2556 B D-0.3931 C D-4.35 A^{2} \\
& -1.10 B^{2}-0.8745 C^{2}-1.34 D^{2} \\
& \\
B=72.00-3.56 & A-2.07 B-2.15 C+3.58 D+1.60 A B+1.31 A C-0.8687 A D \\
& -0.1844 B D+0.3206 C D-15.83 A^{2}-3.50 B^{2}-3.09 C^{2} \\
& -4.80 D^{2} \\
W & =26.55+9.00 A-1.04 B+4.71 C+0.423 D
\end{array}
$$

\section{The actual and predicted value of an independent variable}

Figs. 1 and 2 show the actual value and the expected value of each dependent variable (response) obtained. The actual and expected pulp yield values are shown in Fig. 1(a). Real and expected values are strongly aligned with each other in this figure, with an $\mathrm{R}^{2}$ value of 0.997 . Fig. 1(b) shows that the actual versus the predicted values for the kappa number and its $\mathrm{R}^{2}$ value is 0.998. From Fig. 2(a) the actual versus predicted values for brightness and its $R^{2}$ value was 0.993 . In Fig. 2(b) actual versus predicted values for whiteness and its $\mathrm{R}^{2}$ value was 0.998 . For all responses such as pulp yield, brightness, kappa number and whiteness, their $\mathrm{R}^{2}$ values were 0.997 , $0.993,0.998$ and 0.998 respectively. all responses have high $R^{2}$ values. This $R^{2}$ value represents a slight or negligible difference between the real experimental values and the predicted fit value.

A 3D representation of the yield of the pulp is shown in Fig. 3(a) and (b). The yield of pulp obtained in the 3D representation ranged from 34.68-58.31. The maximum yield achieved was 58.31 percent in the 3D representation of Fig. 3(a) and (b). This was done at a temperature of $160^{\circ} \mathrm{C}$, a 45 percent ethanol concentration, a 15 percent alkali charge, and a pulping time of 130 minutes. The difference between the shapes of the graph between Fig. 3 (a) and (b) was the changing and the constant variables during the experments. 


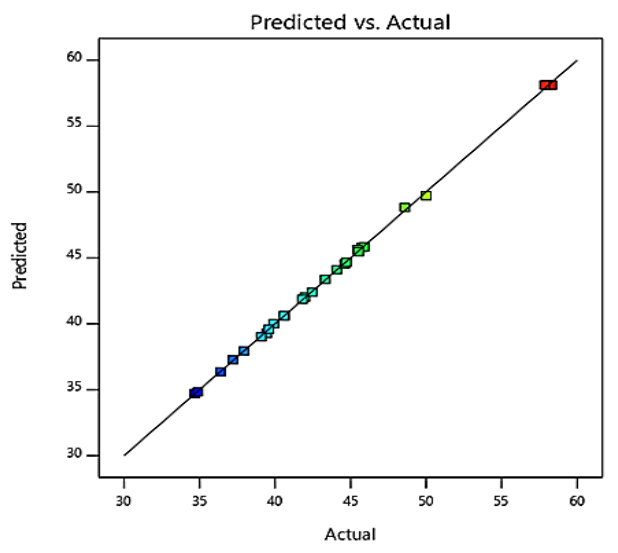

a)

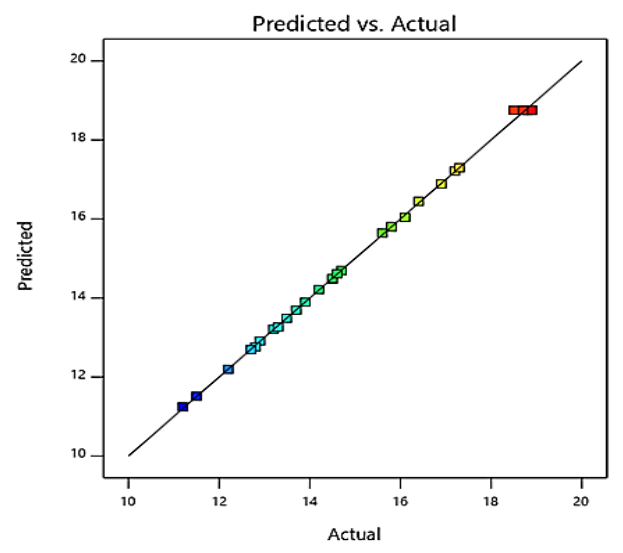

b)

Fig. 1. Actual versus predicted values for: a) pulp yield; b) kappa number

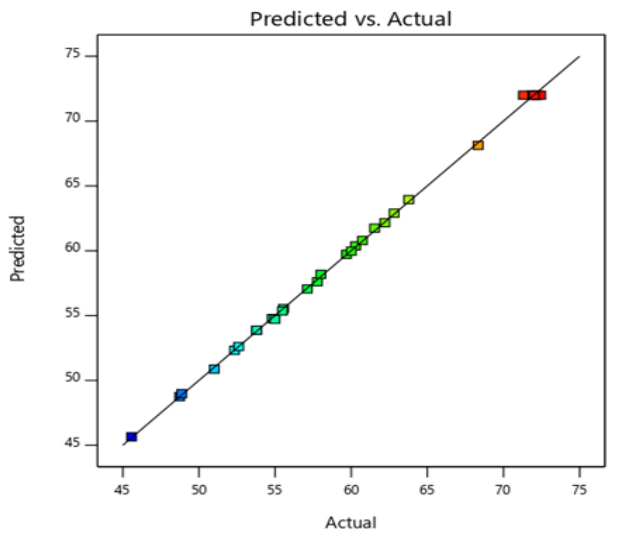

a)

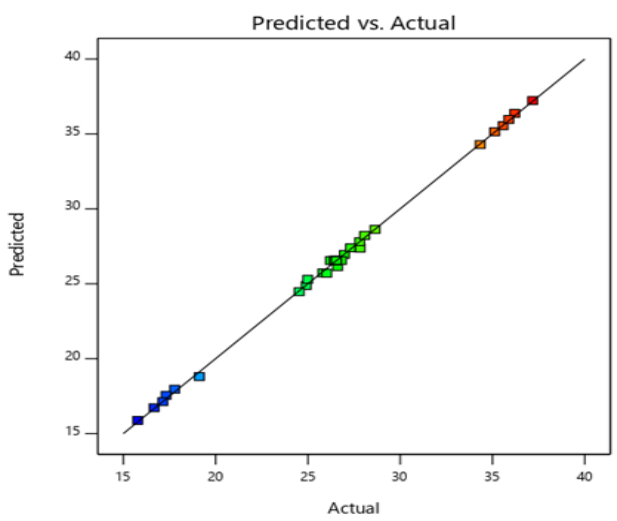

b)

Fig. 2. Actual versus predicted values for: a) brightness; b) whiteness

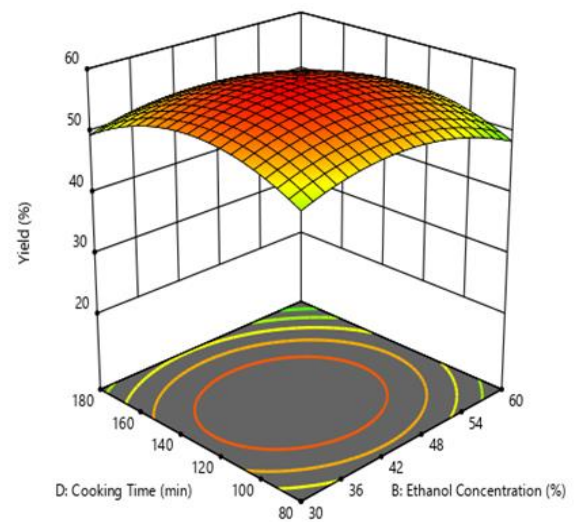

a)

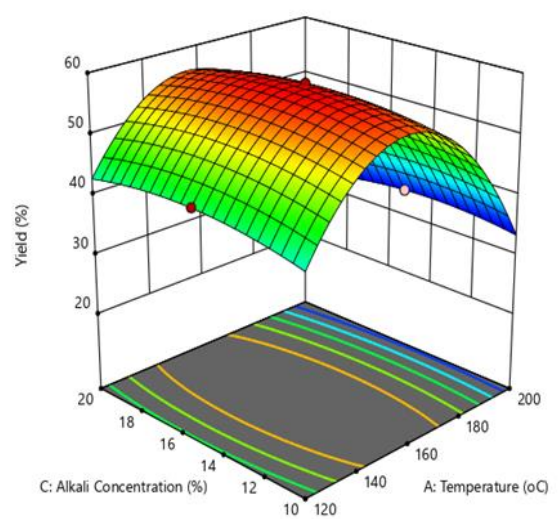

b)

Fig. 3. 3D representation of pulp yield:

a) at varying cooking time and ethanol concentration but temperature at $160^{\circ} \mathrm{C}$ and active alkali at 15 ;

b) at varying active alkali and temperature but ethanol concentration 45 and cooking time at 130 min. 
The 3D representation of the kappa number was shown in Fig. 4. The kappa number obtained for this analysis was 11.2-18.9 percent in Fig. 4(a) and (b). The maximum kappa number was obtained at a temperature of $160^{\circ} \mathrm{C}$, at the ethanol concentration of $45 \%$, at the alkali charge of $15 \%$, and at a pulping time of $130 \mathrm{~min}$. From Fig. 5 the 3D representation of brightness was shown. The 3D diagram in Fig. 5 (a) and (b) represents the brightness of the pulp. From the 3D representation the brightness value obtained between 45.58 and 72.47 percent Fig. 5 (a) and (b). This maximum brightness value was obtained at an ethanol concentration of 45 percent, a temperature of $160^{\circ} \mathrm{C}$, a pulping time of 130 minutes, and at 15 percent alkali charge. The Fig. 6 represents the 3D plot of whiteness. For this study the whiteness obtained was ranged between 15.78 and $37.18 \%$ from Fig. 6(a) and (b). The maximum whiteness for this study was $37.18 \%$ this obtained at a temperature of $200^{\circ} \mathrm{C}$, at ethanol concentration of $45 \%$, at alkali charge of $15 \%$, and at cooking time of $130 \mathrm{~min}$.

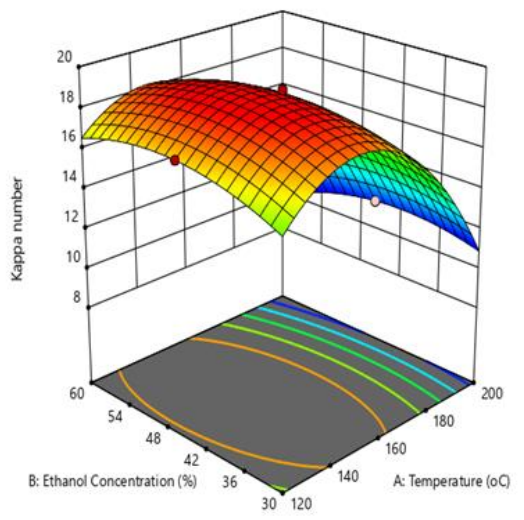

a)

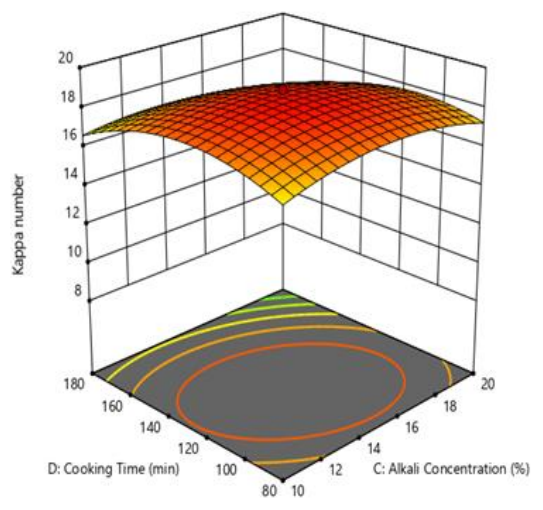

b)

Fig. 4. 3D representation of kappa number:

a) at varying temperature and ethanol concentration but cooking time $130 \mathrm{~min}$ and active alkali at 15 ; b) at varying active alkali and cooking time but ethanol concentration 45 and temperature at $160^{\circ} \mathrm{C}$.

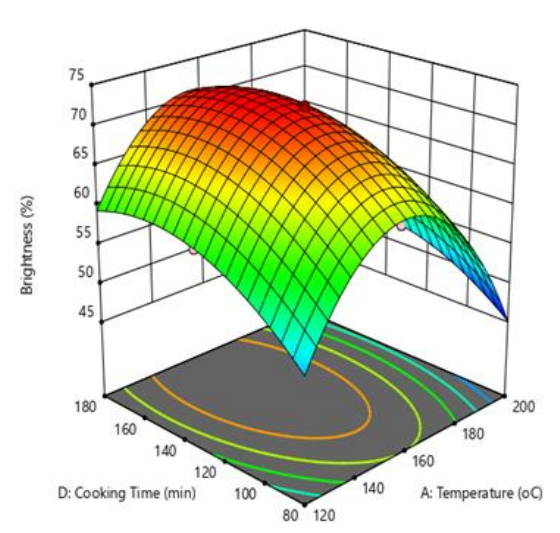

a)

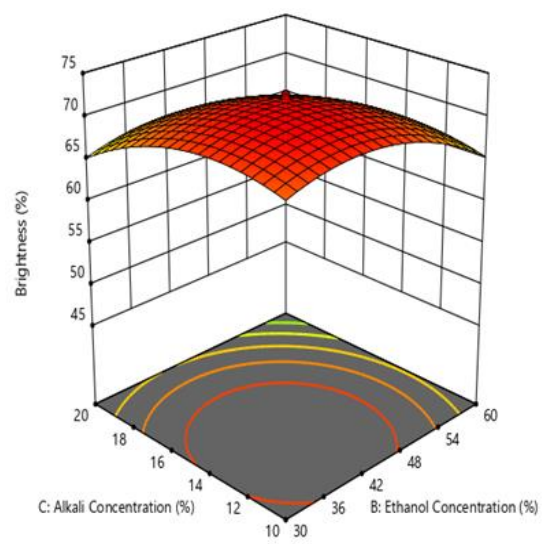

b)

Fig. 5. 3D representation of bright ness:

a) at varying temperature and cooking time but active alkali $15 \%$ and ethanol concentration at $45 \%$;

b) at varying active alkali and ethanol concentration but temperature of $160^{\circ} \mathrm{C}$ and cooking time at $130 \mathrm{~min}$. 


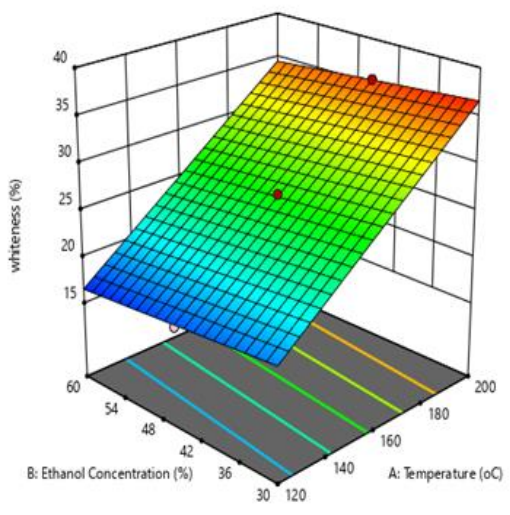

a)

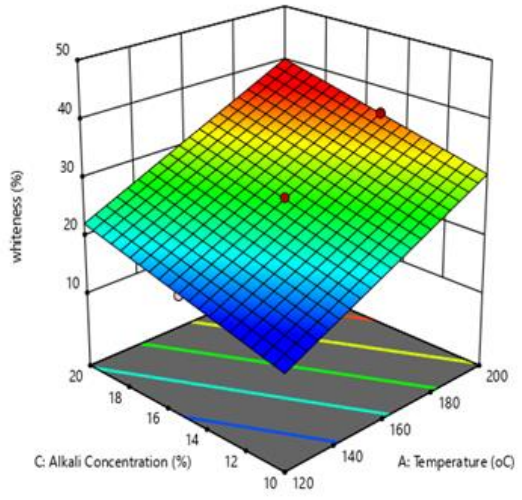

b)

Fig. 6. 3D representation of whiteness:

a) at varying temperature and ethanol concentration but active alkali $15 \%$ and cooking time at $130 \mathrm{~min}$;

b) at varying active alkali and temperature but cooking time of 130 min and ethanol concentration at $45 \%$

\section{Yield of pulp}

The yields p-values for all single factors were much less than 0.0001 for temperature, pulping time, ethanol concentration, and active alkali. The p-value is less than the level of significance ( $\alpha$-value) then the variables has a signficant influence on the response according to Behera et al., [34]. From Table 7 the values for yield, kappa number, brightness and whiteness of the pulp was observed. The pulp yield obtained in this study ranged from 34.68-58.31 percent. The pulp yield obtained in bamboo species (Yushania alpine) was 36.32-55.76 percent. Thus, the current study has higher yield than the yields obtained from bamboo species (Yushania alpine) that performed by Aklilu [15] and the yield obtained from giant reed stem (Arundo donax L.) was 40-50.6\% that reported by Shatalov et al., [22]. The yield obtained from Grevillea robusta in this study was comparable results with the yield obtained from Eucalyptus globulus wood that has the yield of 46.6-58.2\% [14]. Also, yield of Grevillea robusta was comparable yield with the olive tree trimmings which has a yield of $44.2-58.9 \%$ reported by Jiménez et al., [23], the yield obtained from Bambusa procera acher that has a yield of $48.1-58.6 \%$ performed by $\mathrm{Vu}$ et al., [24]. Grevillea robusta has a fewer yields compared with Eucalyptus globulus bark that has the yield of 45.0-59.3\% performed in the study of Neiva et al [14], the yield of cardoon (Cynara cardunculus L.) stalk that has a yield of 44.5-62.0\% that was done by Shatalov and Pereira [25], and the pulp yield obtained from Enset fibers that has the yield of $60.3-86.60 \%$ in the study of Berhanu et al., [18]. From Fig. 1(a) the actual versus predicted values for pulp yield has the $\mathrm{R}^{2}$ value of 0.997 . The predicted and actual values fitted well that means its $R^{2}$ value was approached to one [26]. From equation (4) the model equation for yield implies that the four factors such as temperature, ethanol concentration, active alkali charges and pulping time have inverse relation with the pulp yield obtained. As the delignification reactions at high temperatures are too rapid however, the condensation of lignin and the hydrolysis of carbohydrates are retarded. As the pulping time was continues to increase and the temperature increases, the pulp yield decreases. That have been noted in Enset fibers and giant reed stems [18]. The 3D representation shown in the Fig. 3 (a) and (b) the yield obtained was $34.68-58.31 \%$. The pulp yield significantly affected by single factor as well as interaction effects. The standard deviation and CV (\%) obtained for yield of pulp were 0.1718 and 0.3803 . The lower value of standard deviation and CV (\%) indicates that all values obtained during the experiment are cloth the mean obtained from all data. The value of CV (\%) is less than one indicates that the standard deviation value is less than that of the mean [27]. The sum of square values and F-values for temperature, ethanol concentration, alkali charges, and pulping time were shown in Table 8 . The temperature had the most significant 
effects on the yield it's F-value was 4903.99, followed by ethanol concentration, pulping time and active alkali charges ( see Table 8). The higher value of sum of square and F-value indicates that factors affects the response higher than the lower value of sum of square and F-value [28].

\section{Kappa number}

Kappa number shows the content of lignin or the ability of the pulp to bleach. Its value is ranged from 1 to 100 [29]. For this study the kappa number obtained from Grevillea robusta was 11.2-18.9 from Table 7. This pulps kappa number obtained from Grevillea robusta was comparable with the kappa number obtained by ethanol-alkali pulp from bamboo species (Yushania alpine) that ranged from 11.3-17.3 Aklilu, [15], also compared with bamboo pulp kappa number ranged from 11to 20 lies in the accepted limits of ethanol-alkali pulping that obtained by Neiva et al., [14]. Kappa number for this study was less than that of Eucalyptus globulus from wood that was ranged 8.8-51.1 and from bark was 10.9-63.4 that suggested by Neiva et al., [14]. The actual versus predicted values for kappa number was shown in Fig. 1(b). The actual results were plotted on a $45^{\circ}$ line, whose values was arranged on inclined straight line, starting from the origin. Its acquired $\mathrm{R}^{2}$ value was 0.998 . From equation 5 the kappa number has inverse relationship with temperature, ethanol concentration, active alkali, and pulping time. When temperature, ethanol concentration, active alkali, and pulping time were increased the kappa number was decrease and vice versa. The 3D representation of kappa number in Fig. 4 (a) and (b) the results obtained in 3D was ranged from 11.2-18.9. The kappa number most significantly affected by temperature that means its F-value was 5877.00, and then followed by pulping time, alkali charges, and ethanol concentration( see table 8). Its standard deviation and coefficients of variation for kappa number obtained were 0.092 and 0.607 this shows a fewer variability of the results obtained( see Table 9).

\section{Brightness of the pulp}

The actual versus predicted values for brightness is shown in Fig. 2(a). The actual value was dotted along the predicted value of straight line. For the brightness the $\mathrm{R}^{2}$ value was 0.993 , it suggesting a good correlation between the predictors and the actual variable [30]. From equation (6) the brightness of pulp has inverse relation with temperature, ethanol concentration, and alkali charges but it has direct relationship with the pulping time. When temperature, ethanol concentration, and alkali charges increase above certain point the brightness of the pulp was decrease whereas the cooking time increase the brightness of the pulp was increase. From Table 8 the $p$-value $(\mathrm{p}<0.0001)$ for all single factor that is less than the level of significance that is 0.05 . From the F-value the pulping time has the most significant effects on the brightness of the pulp, followed by alkali charges, ethanol concentration, and temperature(see Table 8). The 3D representation of brightness was shown in Fig. 5 (a) and (b). The maximum brightness obtained was $72.49 \%$. the maximum results was obtained at temperature of $160^{\circ} \mathrm{C}$, ethanol concentration of $45 \%$, and alkali charges of $15 \%$, and pulping time of $130 \mathrm{~min}$. The experimental results from Table 7 the brightness obtained was $45.56-72.49 \%$. The brightness obtained from this study has comparable results with the pulp produced from ethanol-alkali delignification from bamboo species especial from Yushania alpine 45.3-68.3\% reported by Aklilu, [15], also comparable results with eucalypt pulps brightness that ranged from $67-70 \%$ reported by Vazquez et al., [31]. Pulp brightness obtained in this study was greater than the brightness analyzed from giant reed stems ranged from 21.44-58.3\% that performed by Shatalov and Pereira, [25]. The brightness obtained from G. robusta was less than the brightness obtained from E. ventricosum ranged from 46.9- 74.6\% that were done by Berhanu et al., [18].

\section{Whiteness of the pulp}

The predicted and actual value of whiteness of the pulp was shown in Fig. 2(b). The $\mathrm{R}^{2}$ (coefficients of determination) was 0.998. This signifies that the experimental results and 
predicted values are fitted well. From Table 8 the p-values for all single factor was less than 0.0001 this indicates that temperature, ethanol concentration, and alkali charges, and pulping time has significant effects on the whiteness of the pulp. The whiteness of the pulp has a positive relationship with temperature, alkali charges and pulping time as shown from equation (7), that implies that one of the variables increased from those variable was increase the whiteness of the pulp. But for ethanol concentration, the reverse was true. The 3D representation of whiteness in the Fig. 6, the obtained results was ranged from $15.78-37.18 \%$. The maximum result obtained was $37.18 \%$. This maximum result of whiteness was obtained at temperature of $200^{\circ} \mathrm{C}$, ethanol concentration of $45 \%$, and alkali charges of $15 \%$, and pulping time of $130 \mathrm{~min}$. The whiteness of the pulp obtained from E. ventricosum ranged from -1.3-62 was greater than the yield obtained from G. robusta suggested by Berhanu et al., [18]. The standard deviation and CV\% obtained for whiteness was very low which signifies 0.2106 and 0.7934 respectively.

\section{Optimization process variable and the responses}

From Table 10 the optimized results for all process variables such as temperature, ethanol concentration, alkali charges, and pulping time were 159.73, 41.17, 16.79, and 132.26 respectively. At these process variables the optimum yields obtained was 57.79, the optimum kappa number obtained was 18.48 , the optimum brightness obtained was 71.30 , and the optimum whiteness obtained was 28.46. From Fig. 7 the desirability of each parameter and responses were obtained. The desirability for all process variables such as temperature, ethanol concentration, alkali charges, and pulping time were one. But desirability for yield of pulp, kappa number, brightness and whiteness were $0.978,0.946,0.957$ and 0.592 respectively. The yields of pulp, kappa number, brightness have a good desirability but whiteness has a desirability of satisfactory. But the combined desirability for all factors was 0.85 that is a good desirability.

Table 10. Optimization process variable as well as responses of pulp

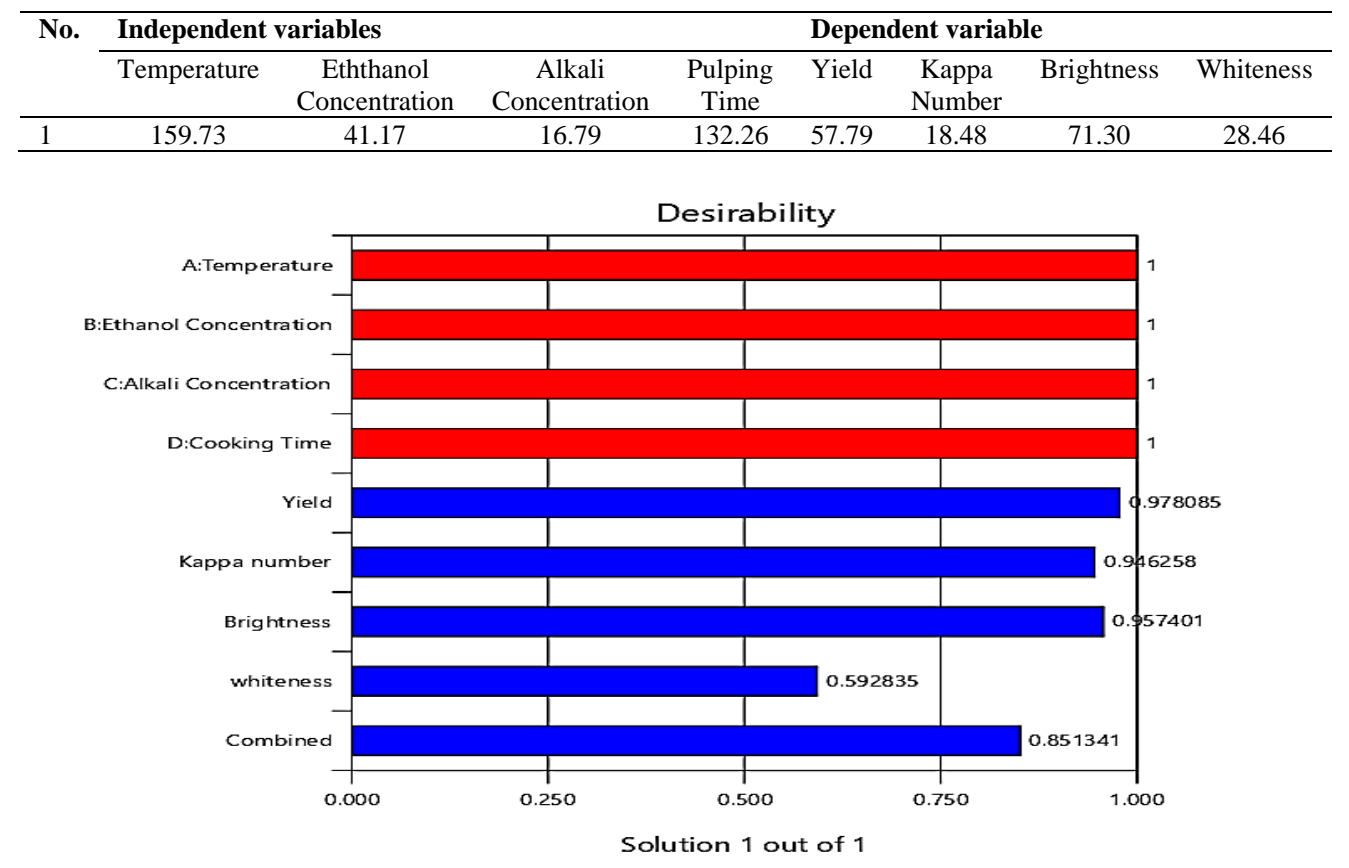

Fig. 7. The Desirability of optimized process variable, responses and combined desirability 


\section{Pulp and paper characterization}

Before the pulp and paper characterization the pulp and paper was bleached by using different reagents [32]. There are three simple stage such as $\mathrm{H}_{2} \mathrm{O}_{2}$ sequential treatments, QPPP methods of treatments like Q-chelating treatment and P-hydrogen peroxide the consecutive bleaching methods without considering oxygen pre-delignification of pulp bleaching. Those three stages were used to bleach the pulp and paper obtained. The ash content paper implies that there may be the residue of chemicals left during manufacturing, at a time of transporting the raw material, pulp through pipe and machinery. The pulp produced from G. rubusta was characterized by physical, chemical and mechanical perspective. Properties of paper like the pulps gamma, thickness, burst, tensile, tear, ash content, copper number, pentose, hydrochloric acid solubility, hydrofluoric acid solubility, denier, tenacity for both wet and conditioned were tasted( see Table 11). From Table 11 the physical characterization obtained results for Grammage was $65.41 \mathrm{~g} / \mathrm{m}^{2}$, and thickness was 0.14 that is comparable results reported by Aklilu [15]. The chemical properties for pulp produced were ash content 0.041 , hydrochloric acid solubility was $102 \mathrm{ppm}$, hydrofluoric acid solubility was $43 \mathrm{ppm}$, and pentose was $2.01 \%$. The mechanical properties of pulp and paper was characterized denier was $1.43 \mathrm{~g} / \mathrm{den}$, tenacity for both wet and conditioned were 1.28 , and 2.26 respectively. In addition to this mechanical properties like burst, tensile, and tear were characterized its value were $4.6,49.73$, and 13.4 respectively.

Table 11. Produced pulp characterization

\begin{tabular}{lcc}
\hline Test type conducted & Units used for measurement & Obtained results \\
\hline Chemical properties & $\%$ & 0.041 \\
Ash content & $\mathrm{Ppm}$ & 102 \\
hydrochloric acid solubility & $\mathrm{Ppm}$ & 43 \\
hydrofluoric acid solubility & $\mathrm{Ppm}$ & 0.36 \\
copper number, & $\%$ & 2.01 \\
Pentose & & \\
Physical properties & $\mathrm{g} / \mathrm{m}^{2}$ & 65.41 \\
Grammage & $\mathrm{Mm}$ & 0.14 \\
Thickness & & 1.43 \\
Mechanical properties & $\mathrm{g} / \mathrm{den}$ & 1.28 \\
Denier & & 2.26 \\
Tenacity & $\mathrm{g} / \mathrm{den}$ & 4.6 \\
Wet & $\mathrm{g} / \mathrm{den}$ & 49.73 \\
Conditioned & $\mathrm{kPa} \mathrm{m}$ & 13.4 \\
Burst & $\mathrm{kN} \mathrm{m} / \mathrm{kg}$ & \\
Tensile & $\mathrm{N} \mathrm{m} / \mathrm{kg}$ & \\
Tear & & \\
\hline
\end{tabular}

This property like burst, tensile, and tear characterized was comparable result that reported by Neiva et al., [33].

\section{Conclusion}

The higher pulp yield was obtained from G. robusta by combining various parameters. The response surface methodology, that is central composite design was used in evaluating the interaction effects of all parameters. For yield, kappa number and brightness, the quadratic model was used, while for whiteness, the linear model was used to evaluate the results. The temperature has the most significant effects on the yield and kappa number of the pulp. Beside, the most significant effects was the pulping time for brightness and and concentration of alkali for whiteness. The optimum yield, kappa number, brightness, and whiteness were $57.79 \%, 18.48$, $71.30 \%$, and $28.46 \%$ respectively. These optimum results were obtained at $159.73^{\circ} \mathrm{C}, 41.17 \%$, $16.79 \%$, and 132.26 minutes respectively. For this analysis desired outcome of combined desirability was 0.85 . The pulp and paper produced was characterized by physical properties, 
mechanical properties and chemical properties. The most common physical properties like grammage and thickness was characterized, its value was $65.41 \mathrm{~g} / \mathrm{m}^{2}$ and $0.14 \mathrm{~mm}$ respectively. Mechanical properties like burst, tensile, tear, and tenacity for both wet and conditioned were determined and its value were $4.6 \mathrm{kPa} \mathrm{m}^{2}, 49.73 \mathrm{kN} \mathrm{m} / \mathrm{kg}, 13.4 \mathrm{~N} \mathrm{~m}^{2} / \mathrm{kg}, 1.28 \mathrm{~g} / \mathrm{den}$, and 2.26 $\mathrm{g} /$ den respectively. Characterization of pulp and paper was comparable to the different studies conducted earlier.

\section{Acknowledgement}

Thanks to the Jimma University Institute of Technology School of Chemical Engineering, the authors want to say that grateful thanks to all laboratory technicians have carried out and facilitated this laboratory work.

\section{Reference}

[1] Beroual, M., Trache, D., Mehelli, O., Boumaza, L., Tarchoun, A.F., Derradji, M. and Khimeche, K.. Effect of the delignification process on the physicochemical properties and thermal stability of microcrystalline cellulose extracted from date palm fronds. Waste and Biomass Valorization, 2020, pp.1-15.

[2] Alén, R. Manufacturing Cellulosic Fibres for Making Paper: A Historical Perspective. In Technological Transformation in the Global Pulp and Paper Industry, 2018 1800-2018 (pp. 13-34). Springer, Cham

[3] Bajpai, P.. Pulp and paper industry: chemicals, 2015, Elsevier.

[4] Larson, E.D., Consonni, S., Katofsky, R.E., Iisa, K. and Frederick, W.J. A cost-benefit assessment of gasification-based biorefining in the kraft pulp and paper industry. The Trustees of Princeton University, 2007.

[5] Timmers, T., Janssen, L., Van der Weegen, W., Das, D., Marijnissen, W.J., Hannink, G., van der Zwaard, B.C., Plat, A., Thomassen, B., Swen, J.W. and Kool, R.B. The effect of an app for day-to-day postoperative care education on patients with total knee replacement: Randomized controlled trial. JMIR mHealth and uHealth, 2019 7(10), p.e15323.

[6] Hedlund, M. and Wejbro, M. Design Program for Dessie Campus, Wollo University, Ethiopia, 2012

[7] Kunkel, Günther. Flowering trees in subtropical gardens. Springer Science \& Business Media, 2012.

[8] Kuyah, S., Sileshi, G.W., Luedeling, E., Akinnifesi, F.K., Whitney, C.W., Bayala, J., Kuntashula, E., Dimobe, K. and Mafongoya, P.L. Potential of agroforestry to enhance livelihood security in Africa. In Agroforestry for Degraded Landscapes. Springer, Singapore, 2020(pp. 135-167)

[9] Kassa, H., Tadesse, W., Alem, S., Teshome, B. and Garedew, E. Book of Abstracts on Agroforestry, Area Exclosure, Participatory Forest Management, Management of Dry Forests and Plantations, 2015

[10] Lin, B. and Li, X., 2011. The effect of carbon tax on per capita $\mathrm{CO} 2$ emissions. Energy policy, 39(9), pp.5137-5146.

[11] Belay, F.A. and Ababa, A. The potential of native arbuscular mycorrhizal fungi inoculation to improve the dry evergreen Afromontane forests restoration efforts in Ethiopia, 2020

[12] Xu, W.S., Douglas, J.F., Xia, W. and Xu, X. Investigation of the Temperature Dependence of Activation Volume in Glass-Forming Polymer Melts under Variable Pressure Conditions. Macromolecules, 2020, 53(16), pp.6828-6841. 
[13] Born $\varnothing$, M.L., Rønn, R. and Ekelund, F. Is wood ash amendment a suitable mitigation strategy for N2O emissions from soil. Science of the Total Environment, 2020, 713, p.136581.

[14] Neiva, D.M., Gominho, J. and Pereira, H. Modeling and optimization of Eucalyptus globulus bark and wood delignification using response surface methodology. BioResources, 2014, 9(2), pp.2907-2921.

[15] Aklilu, E.G. Optimization and modeling of ethanol-alkali pulping process of bamboo (Yushania alpina) by response surface methodology. Wood Science and Technology, 2020, 54(5), pp.1319-1347.

[16] Egbewole, Z.T., Rotowa, O.J. and Omoake, P.O. Evaluation of fibre quality of Bambusa Vulgaris (bamboo) as a raw material for pulp and paper production. PAT, 2015, 11(2), pp.188-202.

[17] Uskokovic, V., Uskokovic, E., Uskokovic, T. and Wu, V. And All the World a Dream: Memory Outlining the Mysterious Temperature-Dependency of Crystallization of Water, aka the Mpemba Effect. Substantia, 2020, 4(2).

[18] Berhanu, H., Kiflie, Z., Neiva, D., Gominho, J., Feleke, S., Yimam, A. and Pereira, H. Optimization of ethanol-alkali delignification of false banana (Ensete ventricosum) fibers for pulp production using response surface methodology. Industrial Crops and Products, 2018,126, pp.426-433.

[19] Habib, A. and Rahman, M.S. Balancing decoding speed and memory usage for Huffman codes using quaternary tree. In Applied Informatics, 2017 (Vol. 4, No. 1, p. 5). Springer Berlin Heidelberg.

[20] McShane, B.B. and Gal, D. Statistical significance and the dichotomization of evidence. Journal of the American Statistical Association, 2017, 112(519), pp.885-895.

[21] Owolabi, M.O., Sarfo, F., Akinyemi, R., Gebregziabher, M., Akpa, O., Akpalu, A., Wahab, K., Obiako, R., Owolabi, L., Ovbiagele, B. and Owolabi, M.O. Dominant modifiable risk factors for stroke in Ghana and Nigeria (SIREN): a case-control study. The Lancet Global Health, 2018 6(4), pp.e436-e446.

[22] Shatalov, A.A. and Pereira, H. High-grade sulfur-free cellulose fibers by pre-hydrolysis and ethanol-alkali delignification of giant reed (Arundo donax L.) stems. Industrial Crops and Products, 2013 43, pp.623-630.

[23] Jimenez, L., Rodríguez, A., Díaz, M.J., Lopez, F. and Ariza, J. Organosolv pulping of olive tree trimmings by use of ethylene glycol/soda/water mixtures. Holzforschung, 2004, 58(2), pp.122-128.

[24] Vu, T.H.M., Pakkanen, H. and Alén, R. Delignification of bamboo (Bambusa procera acher): Part 1. Kraft pulping and the subsequent oxygen delignification to pulp with a low kappa number. Industrial Crops and Products, 2004, 19(1), pp.49-57.

[25] Shatalov, A.A. and Pereira, H. Dissolving grade eco-clean cellulose pulps by integrated fractionation of cardoon (Cynara cardunculus L.) stalk biomass. Chemical Engineering Research and Design, 2014 92(11), pp.2640-2648.

[26] Tapouk, F.A., Nabizadeh, R., Nasseri, S., Mesdaghinia, A., Khorsandi, H., Yousefi, M., Alimohammadi, M. and Khoobi, M. Embedding of L-Arginine into graphene oxide $(G O)$ for endotoxin removal from water: Modeling and optimization approach. Colloids and Surfaces A: Physicochemical and Engineering Aspects, 2020, 607, p.125491.

[27] Abbasi, F., Yaraki, M.T., Farrokhnia, A. and Bamdad, M. Keratin nanoparticles obtained from human hair for removal of crystal violet from aqueous solution: Optimized by Taguchi method. International Journal of Biological Macromolecules, 2020, 143, pp.492-500. 
[28] Seidl, R., Weiss, S., Zikulnig, Rusch, E.M. and Kandelbauer, A. Response surface optimization for improving the processing behavior of melamine formaldehyde impregnation resins. Journal of Applied Polymer Science, 2021, 138(7), p.50181.

[29] Kumar, V., Kumar, A., Chhabra, D. and Shukla, P. Improved biobleaching of mixed hardwood pulp and process optimization using novel GA-ANN and GA-ANFIS hybrid statistical tools. Bioresource technology, 2019, 271, pp.274-282.

[30] Ndehedehe, C.E. and Ferreira, V.G. Assessing land water storage dynamics over South America. Journal of Hydrology, 2020 580, p.124339.

[31] Vázquez, D.P. Multiple effects of introduced mammalian herbivores in a temperate forest. Biological invasions, 2002, 4(1-2), pp.175-191.

[32] Zainith, S., Purchase, D., Saratale, G.D., Ferreira, L.F.R., Bilal, M. and Bharagava, R.N. Isolation and characterization of lignin-degrading bacterium Bacillus aryabhattai from pulp and paper mill wastewater and evaluation of its lignin-degrading potential. 3 Biotech, 2019, 9(3), p.92.

[33] Neiva, D., Fernandes, L., Araújo, S., Lourenço, A., Gominho, J., Simões, R. and Pereira, H. Chemical composition and kraft pulping potential of 12 eucalypt species. Industrial Crops and Products, 2015, 66, pp.89-95

[34] Behera, S.K., Meena, H., Chakraborty, S. and Meikap, B.C. Application of response surface methodology (RSM) for optimization of leaching parameters for ash reduction from lowgrade coal. International Journal of Mining Science and Technology, 201828(4), pp.621629.

[35] Yue, Z., Huang, C., Zhu, H., Wang, J., Yao, P. and Liu, Z. Optimization of machining parameters in the abrasive waterjet turning of alumina ceramic based on the response surface methodology. The International Journal of Advanced Manufacturing Technology, 2014, 71(9-12), pp.2107-2114.

Received: January 18, 2021

Accepted: February 20, 2021 